\title{
Green Design and Manufacturing Technology of the Rare Earth Permanent Magnet Electrical Machines

\author{
Ji-Rong Yang ${ }^{1,2, a^{*}}$, Shi-Wei HU ${ }^{2, b}$, Gan ZHANG $^{1, c}$, \\ Zhen-Jie GONG ${ }^{1, \mathrm{c}}$
}

${ }^{1}$ College of Mechanical Engineering, Hunan University of Arts and Science, Cangde, 415000, China

${ }^{2}$ Hunan De Yi Wei energy conservation Technology company, Changde, 415000, China

ayjrtt1028@sina.com, ${ }^{\mathrm{b}} 13807369487 @ 189 . c n,{ }^{\mathrm{c}} \mathrm{zg} 1128 @ 163 . c o m$

${ }^{*}$ Corresponding author

Keywords: Rare earth permanent magnet electrical machines; Green design; Green manufacturing

Abstract. Green design and manufacture is a kind of sustainable development model in modern manufacture. This paper focuses on green design concept, application and selection of green materials and product manufacturing of the Rare earth permanent magnet electrical machines.

\section{Introduction}

In the new era, in addition to facing competition in the quality and cost of the product, some enterprises in the manufacturing industry have more severe challenges how to break the green barriers. The green design, green manufacturing and green materials to use have not been paid enough attention. Many companies still go the old way that only to pay attention to the quality, cost, efficiency of the products, but to ignore the pollution to the environment from the processing using and product obsolescence. If rare earth permanent magnet electrical machines would fundamentally prevent pollution, conserve resources and energy, the key is to design and manufacture. It is late to take preventive measures after the adverse environmental consequences have been produced, so before manufacturing products and processes should be tried to prevent negative effects on the environment. This is the basic idea of green design and manufacturing in rare earth permanent magnet electrical machines.

In this paper, based on the concept and connotation of green design and manufacturing [1], the green design method, the selection of green materials and some green manufacturing technology in rare earth permanent magnet electrical machines were proposed. These new technology are used to improve the resource utilization rate, lower costs, reduce environmental pollution, face with the challenges of the international green trade barriers and carry out the strategy of sustainable development in the manufacturing.

\section{Concept of Green Design and Manufacturing in Rare Earth Permanent Magnet Electrical Machines}

Green design and manufacture in the rare earth permanent magnet electrical machines is a modern manufacturing model with comprehensively consideration of environmental impacts and resource efficiency, and it is an important manifestation of the strategy of sustainable development in the manufacturing industry. It is defined as a modern design-manufacturing model with comprehensively consideration of environmental impacts and resource efficiency, and its goal is to make negative impact on the environment minimum, resource efficiency highest, economic and social benefits of enterprises coordinate optimization in the entire product life cycle from design, manufacture, packaging, transportation, using to discard processing.

Its procedure is to use green production process such as green design, green materials, green technology, green packaging and green management to produce green products. Green manufacture is essentially different from the traditional method from the product design, technology to tooling. It is essentially the embodiment of human society, sustainable development strategy in the present 
manufacturing, and its connotation is that the product has green characteristics in the whole life cycle.

\section{Green Design Method in Rare Earth Permanent Magnet Electrical Machines}

The concept of green design in rare earth permanent magnet electrical machines can be summarized as: it is modern design method which is based on the entire life cycle of the product and taken environmental resource attributes of the products as the core. In the design, in addition to considering the product's features, performance, life and cost, the impact on the environment and resources in production, using, waste and recycling process must also be considered. It mainly includes the following respects:

Modeling of green products. That creating a system evaluation model of green product is the key of green design. For example, in the process of designing the parts of a Stator, rotor, inner and outer shell, etc., the multi-objective fuzzy optimization design is used to make the weight the lightest, the volume the smallest, the timber and the energy consumption the least [2]. Now the evaluation index system of green product and the formulation principles of the evaluation criteria have been proposed, the fuzzy evaluation method was used to evaluate the "greenness", and the corresponding evaluation tools was developed.

Disassembly design of the products. The characteristics without disassembly will not only result in the waste of a large number of reusable parts and components but cause serious environmental pollution due to poor disposal of waste. The disassembly has become an important part of the mechanical design. As one of the main contents of the green product design, disassembly requires to be taken as an evaluation criterion of structural design in the early stages of product design.

Recyclable Design of Products. Recyclable design is to take full account of some issues relating to the recoverability such as recycling possibility, recycling value, recycling method, recycling structural process in the early stage of product design to eventually obtain the largest use of resources and energy of the parts and materials and a minimum of environmental pollution. There are the following aspects in the recyclable design: (1) recyclable materials and signs; (2) recyclable processes and methods; (3) recyclable economy evaluation; (4) recyclable structural design.

\section{Cost Analysis of Green Products in Rare Earth Permanent Magnet Electrical Machines}

Because the performance such as product recycling and re-use must be considered in the early stage of product design, we should take into account of the alternative of pollutants, disassembly, re-use cost, corresponding environmental cost of special products in the cost analysis. Whether an enterprise expenditures environmental costs, there would exits the difference of the product cost, and the same environmental projects in actual costs between countries or regions would also form the cost differences. Therefore, each design decision should do cost analysis on green products in order to design the product with higher "green level" and lower total costs.

Structural Design of the Product. In addition to satisfying the basic requirements of ordinary products, green products mainly consider the ease of disassembly and recycling of the structure. Disassembly is the premise of the waste recycling and the recycling is the guarantee of the re-use of waste materials. The research of the structural design includes: (a) the research of the design method on product disassembly; (b) the establishment of disassembly evaluation index system; (c) the division of the disassembly structural module and its structural design; (d) the research of the recovery process and method; (e) the performance design on the product environmental.

Different products may have different effects on the environment, so we should meet the environmental requirements with the conditions of product performance as far as possible when designing.

Performance Design of the Product Resource. In order to make the product resources to get the reasonable exploitation and configuration, the main contents of the design are: (a) the model establishment of the resource consumption in the product life cycle; (b) the characteristics analysis of resource consumption in the production process.

Green Design of the Ventilation Cooling System. The ventilation and cooling system used by the traditional motor is also an important part of the environment whose influences are: working 
medium pollution on the environment due to the leakage, noise harmful to the environment, the destruction of natural resources because of energy costs [3]. The main fault of the Ventilation cooling system in the rare earth permanent magnet electrical machines is leak. The reasons are: one is sealed badly; one is the damage to the Radiating element. Leak causes the resource waste and environmental pollution.

\section{Choice of Green Materials in Rare Earth Permanent Magnet Electrical Machines}

Materials are the basis constituting the rare earth permanent magnet electrical machines. Now an important development direction of the green rare earth permanent magnet electrical machines is that the use proportion of green materials continues to increase. Green materials, also known as environmental coordination materials or eco-materials, have good use performance or functionality, less consumption to resource and energy, less pollution on ecology and environment, benefit to human health, high recycling rate or biodegradable recycling. It can coexist with environmental coordination in the whole process from preparation, use and disposal to regeneration recycling.

The traditional methods selecting material can not meet the requirements of green products and green design, so we should consider the choice of materials in a broader perspective not only the basic performance but the environmental attributes. Now the main principles of selecting green material in the rare earth permanent magnet electrical machines include: (1) the advanced nature of the material performance; (2) the coordination compatibility between materials and environment including easy processing, low poison, small pollution; (3) to use materials without coating and with easy-to-recycle, renewable, decomposition or degradation as far as possible; (4) to maximize the use of parts and materials with a high recovery; (5) to minimize the types and quantities of the material.

\section{Manufacturing Method of Green Machinery in Rare Earth Permanent Magnet Electrical Machines}

Green manufacturing technology is the modern manufacturing model with comprehensive consideration of environmental impact and resource efficiency under the premise of guarantee the product's features, quality and cost. It enables the product to economize resources and energy and to do not produce environmental pollution or to minimize environmental pollution in the entire product life cycle from the design, manufacture, use to the scrapped. Environmentally friendly manufacturing technology is to minimize environmental pollution and create a safe and comfortable working environment in the manufacturing process, and its contents include reducing waste generation, waste emissions, the generation of toxic and hazardous substances, properly handling toxic and hazardous substances, lessening vibration and noise, regulating temperature and air purification, recycling and reusing of waste. The following briefly describes some green manufacturing technology:

Apply Casting Aluminum Technology Precision Forming Process. We apply casting aluminum technology Precision forming process on the parts of a Stator, rotor, inner and outer shell, etc.of the rare earth permanent magnet electrical machines Precision forming process. also known as little chip processing, can get parts or fine blanks by mainly utilizing some processing methods such as the casting, forging, cold extrusion and powder metallurgy. It has significant technical and economic benefits that can achieve a variety of cold and hot process and a variety of composite materials for selection, and combine organically materials and technology, so it is a breakthrough in mechanical manufacturing technology. For manufacturing industry of light industry machinery, precision forming process can not only economize energy and material consumption in the traditional blank manufacturing, but also greatly reduce the manufacturing cycle and production costs.

\section{High-Speed Cutting Machine Tools}

It is well known that the dry machining in the cutting area will generate a lot of cutting heat, and if the heat is not timely distributed out, the machine would be uneven heated to produce thermal 
deformation which is an important factor on the process precision. So the machine should install cycle cooling system to get away cutting heat, and own good insulation in the structure. The experiments show that the ideal conditions of dry cutting is in the high-speed cutting conditions to reduce the thermal spread to the workpiece, tool and machine.

Greening on Rare Earth Permanent Magnet Electrical Machines. For achieving the greening on the life cycle of rare earth permanent magnet electrical machines, it is essential to implement green use in rare earth permanent magnet electrical machines. The rare earth permanent magnet electrical machines mostly work in open and its job sites change frequently, so it is subject to the influence of many factors such as temperature, pollution, traffic and weather. That taking effective measures at the job sites such as the green using policies, green maintenance and repairs can be effective in preventing mechanical failure and ensuring the good rate of the equipment. That reducing correspondingly waste emissions harmful to the environment can improve the mechanical life, that is, it economizes resources.

\section{Conclusion}

Green design and manufacture in rare earth permanent magnet electrical machines is an important part of sustainable human development strategy, and should be also a key consideration to every enterprise. The rise and development of green products is the irreversible trend, and is the tremendous progress of solving the environment, resources and sustainable development. It will have a profound impact on the future of mankind's survival and development.

\section{Acknowledgments}

Union of provinces and cities project of Hunan Province :The research and industrialization of the super power direct drive disk motor about magnetic matrix [2016]; Project (XJF2011[76]) supported by the grant of the 12th Five-Year Plan for the construct program of the key discipline (Mechanical Design and Theory) in Hunan province; Project (15CY008) supported by Industrialization Development Project of Technological Achievements of Universities in Hunan Province; Project (2014GK1043) supported by Hunan Major Special Projects of Science and Technology ;Project (XJT [2014] 239) supported by Cooperative Demonstration Base of Universities in Hunan, "R \& D and Industrialization of Rock Drilling Machines".

\section{References}

[1] LIU Cuijuan ZHONG Xia.Apply the Green Design Concept to the Construction Machinery Industry.Construction Machinery Technology \& Management, 2012（1）:119-121

[2] Luo Youxin Che Xaioyi Yang Jirong Liu Qiyuan Wang Chao. Grey Robust Optimization Design of High Dimension Multi-objective and Its Achieving with Matlab.Transactions of the Chinese Society for Agricultural achinery, 2008, 39(8):157-161

[3] LY LJ U NGBERG.Mate $r$ ials select ion a nd design for development of su st ai nable product s.Materials\& Design, 2005(12):1-14.

[4] C.J. Liu and X. Zhong: Construction Machinery Technology \& Management Vol. 1 (2012), p. 119

[5] Y.X.Luo, X.Y. Che, J.R. Yang, et al.. Transactions of the Chinese Society for Agricultural Machinery Vol. 39 (2008), p. 157

[6] L. L. Ngberg. Materials\& Design Vol. 12 (2005), p. 1 